\title{
The effect of receiving thyroid hormone replacement on the dysphonia severity index for congenital hypothyroid children
}

Heba Mahmoud Farag ${ }^{1 *} \mathbb{D}$, Aisha Fawzy Abdel Hady ${ }^{1}$, Asmaa Abdel Hamid ${ }^{1}$ and Hend Soliman²

\begin{abstract}
Objectives: Dysphonia is a common compliant in hypothyroid patients. Subjective voice changes could be clearly found in congenital hypothyroid children (CHC); however, the early treated children with thyroid hormone replacement (THR) may not experience dysphonia. The objective of this study is to determine if the CHC who were receiving early THR would have objectively measurable changes on vocal function as assessed by the dysphonia severity index (DSI).

Methods: Participants were 29 children aged from 6 to 12 years. Fifteen children had congenital hypothyroidism on eltroxin therapy started before the age of 1 year and 14 were typically developing children (TDC). All children did not have voice compliant. DSI was calculated for all children through the measure of maximum phonation time (MPT), highest frequency ( $F_{0}$-high), lowest intensity (l-low), and jitter percent (j \%).

Results: CHC receiving early THR were not significantly different from TDC on DSI value; however, both groups showed significant difference on MPT and $\mathrm{F}_{0}$-high. Degree of voice changes by DSI in males was significantly higher than females in $\mathrm{CHC}$ on eltroxin therapy while no significant difference regarding gender has been found on DSI in TDC.

Conclusions: The results suggested that there is no evidence of DSI objective voice changes in CHC receiving THR compared to TDC, yet separate objective voice measures alternations had been found in CHC. This highlights the importance of achieving efficient neonatal screening programs for $\mathrm{CHC}$ and providing strong support to initiate early THR to avoid any alternation of laryngeal function.
\end{abstract}

Keywords: Dysphonia, Dysphonia severity index, Congenital hypothyroid children

\section{Background}

The voice is a significant element that defines self-assurance and the socially appropriate attitude of a person. A good voice is a fundamental constituent of the evaluation of oneself. It reduces the social and physiological impediments of an individual [1]. The influence of hormones on the voice and larynx has been a subject of interest in laryngology. Although there are various hormones in the

\footnotetext{
*Correspondence: hebafarag2009@hotmail.com

1 Phoniatrics, Phoniatric Unit, ENT Department, Faculty of Medicine, Cairo University, Giza, Egypt

Full list of author information is available at the end of the article
}

body, it has been evident that sex hormones and thyroid hormones directly affect the voice $[2,3]$. The impact of hormones on voice continues throughout human life and differs from males to females. The voice pitch could be one of the principal factors that influence the perception of gender based on the voice [4].

Thyroid hormones stimulate the development of speech, voice, language, hearing, and all developmental skills. Congenital hypothyroidism $(\mathrm{CH})$ can cause language, voice, and other developmental disturbances in children [5]. It was reported that rough crying could be one of the clinical symptoms common at birth [6], which 
might occur in up to $20 \%$ of cases of congenital hypothyroidism [7]. Dysphonia in $\mathrm{CH}$ is usually gradual and slowly progressive; thus, the patient may not notice the voice change. The voice features associated with hypothyroidism involve decreased pitch, voice weakness, and reduced range of voice [8]. The exact mechanism behind these voice changes is not clear. Typically, the anterior pituitary gland releases thyroid-stimulating hormone (TSH). It results in the release of T4 and T3 by the thyroid gland. Thyroid hormones increase the body's rate of metabolism. In hypothyroidism, dysphonia may result from the deposition of polysaccharides and the accumulation of fluids in vocal folds, thus increasing their thickness [9]. The thickening of vocal folds leads to decreased frequency of their vibration. Dysphonia could also be caused by excess levels of thyroid hormones [8]. Receptors for thyroid hormones have been detected in the larynx, and laryngeal development is substantially affected by thyroid hormones [10].

Subjective assessment of voice in cases of thyroid hormones disturbances has been studied in several types of research; however, the studies about the objective voice assessment in hypothyroidism are limited [11]. Few studies about objective voice assessment in $\mathrm{CH}$ found a considerable level of congenital hypothyroid newborns having voice deviations. Moreover, they pointed out that even after a month of treatment, some children still had vocal disturbances with the hormone levels within standard patterns $[2,12]$. Acoustic and aerodynamic measures are commonly used to evaluate voice changes objectively. Although these measures simplify voice signals and are easy to interpret, their correlation with the subjective evaluation of dysphonia remains uncertain [13].

Dysphonia severity index (DSI) is a tool capable of measuring the multidimensional elements of the voice. The index was created by correlating the results of a study involving 387 subjects using acoustic, aerodynamic, self-reporting measurements, and auditory-perceptual assessment methods. Therefore, the DSI can be reliably used as an objective simple multi-parametric tool because it strongly correlates with the subjective degree of dysphonia. DSI is computed by mean of its constituents; ( $\mathrm{F}_{0}$-high), (I-low), (MPT), and j\% [14].

Nevertheless, DSI can be influenced by agents such as age, gender, and instrument [15]. The studies about DSI are mainly restricted to adults. The effect of age and gender on DSI in a normal population has been studied by Hakkesteegt et al. [16]. In the age range of 20-79 years, they found that $\left(\mathrm{F}_{0}\right.$-high) was decreased with the increase of age in both males and females; however, (I-low) decreased only in females.

Children have constant voice quality variations because of their laryngeal structural difference from adults [17].
Pediatric dysphonia is caused by vocal fold nodules, vocal fold paralysis, velopharyngeal insufficiency, and hormonal disorders [18]. Although there are tools available that assess dysphonia in children, such as voice range profile (VRP) [19] and acoustic voice quality index [20], the DSI was limitedly used to assess dysphonia in children.

Screening for hypothyroidism in newborns and early thyroxin replacement has a noticeable effect on decreasing cognitive and voice problems in (CHC) [21]. However, mild mental, speech, and voice disturbances may be continued even with early hormonal therapy for children with congenital hypothyroidism [22]. However, no studies are available about the use of DSI to assess objective voice measures in $\mathrm{CHC}$ receiving THR. Consequently, DSI scores in those children need to be investigated. The current study aims to assess the DSI scores in CHC receiving replacement therapy and compare it to measures of DSI in normal children to determine the effect of hormonal replacement and whether any subtle voice alternations might necessitate follow-up.

\section{Method \\ Participants}

Participants were 29 children aged 6-12 years. Fifteen children ( 9 males and six females) were diagnosed by neonatal screening to have hypothyroidism. All congenital hypothyroid children were on thyroid hormone therapy for 1 year with controlled hypothyroidism. Fourteen typically developing children (7 males and 7 females), age- and gender-matched served as controls. Inclusion criteria for the control group were cooperative children with subjective average intellectual abilities; children with any voice compliant were excluded. Exclusion criteria for $\mathrm{CHC}$ were patients with acquired hypothyroidism, delayed treatment after 1 year, patients with associated disorders that may have affected the voice, such as patients with childhood vocal fold nodules, vocal folds paralysis, or other apparent communicative, cognitive, genetic, and hearing disorders.

All children were subjected to the protocol of assessment applied in the Diabetes, Endocrine and Metabolism Pediatric Unit (DEMPU), Cairo University Children Hospital, and the Phoniatric Unit, Kasr El Aini Hospital. The study was approved by the ethical committee of the department.

\section{Procedures}

\section{Elementary diagnostic procedures}

History taking involved the age of the child, the age of detection of congenital hypothyroidism and the start of therapy, any signs or symptoms found, and any complaint about voice, including (hoarseness, soreness, frequent throat clearing, the presence of associated congenital 
disorders or hearing disorders), the dose of eltroxin therapy, the control of symptoms and continuity of talking therapy, family history of similar conditions or other endocrinopathies, perinatal history, developmental history, and history of childhood illness. Subjects under study had no complaint about their voices; no abnormality was detected regarding perinatal, natal, and developmental histories. All children were subjected to clinical examination, general examination, ear, nose, and throat examination, including external and internal laryngeal examination. No abnormalities were found. The auditory perceptual assessment was done for subjective voice assessment, and there was no detectable auditory dysphonia.

\section{Clinical diagnostic aids}

Video recorded flexible fiberoptic nasopharyngolaryngoscopy (Xion EF- N 6186), and stroboscopy (Xion Endostrob-DX) was done. No laryngeal abnormalities could be detected.

\section{Additional instrumental measures}

The parameters of DSI were measured for all children to calculate the DSI $\left[\mathrm{F}_{0}\right.$-high in $\mathrm{Hz}$, I-low in $\mathrm{dB}$ sound pressure level (SPL), MPT in seconds, and ( $j \%)$ ]. Assessment of all parameters was done in the acoustically treated room. The subject was instructed to sit comfortably using a dynamic microphone with a $30-\mathrm{cm}$ distance between the subject and microphone.

\section{$\mathrm{F}_{0}$-high and I-low}

To measure $F_{0}$-high and I-low voice range profile (VRP), a module of Computerized Speech Lab model 4500 (Kay Elemetrics., Lincoln Park, NJ, USA) was used. $\mathrm{F}_{0}$-high was measured by asking the participant to phonate the vowel /a/ with a comfortable pitch and reach the highest pitch. The participant was asked to phonate /a/ as softly as possible with a comfortable pitch to obtain the I-low. The examiner molded both measurements to the participant to attain the most relevant $\mathrm{F}_{0}$-high and I-low measures. The participant was encouraged to watch the visual feedback on the VRP screen; the examiner also helped the participant reach the best trial.

\section{MPT}

The participant was instructed to phonate a sustained vowel /a/ as long as possible at a comfortable pitch and loudness. After deep inhalation, the phonation sample was recorded using the CSL 4500 (Kay Elemetrics). Three trials were required to measure MPT to obtain the longest one needed for assessing DSI.

\section{Jitter\%}

The participant was instructed to phonate vowel /a/ at a comfortable pitch and loudness for $5 \mathrm{~s}$. Phonation samples were recorded and analyzed using the advanced Multidimensional Voice Program (MDVP) CSL 4500 (Kay Elemetrics). To record and analyze the phonatory sample, Jitter\% was calculated on a stable middle segment of $3 \mathrm{~s}$ duration to get a voice sample representing the individual's vocal stability at the time of assessment.

The DSI was calculated for each child using the following equation [10]

DSI $=0.13 \times$ MPT $+0.0053 \times$ F0-High- $0.26 \times$ I-low-1.18 $\times$ Jitter $(\%)+12.4$

A pilot study was carried out on five children (2TDC and $3 \mathrm{CHC}$ ) prior to the study to ensure the DSI's applicability to the Arabic-speaking children. A pilot study revealed that the DSI was applied to the children.

\section{Statistical analysis}

Sample size was calculated based on the previous work by Pebbili et al. [23]. The expected difference in DSI between hypothyroidism and control expected to be 1.5 \pm 1.3 . Using power $80 \%$ and $5 \%$ significance level; 13 participants are required in each group. Sample size calculation was achieved using PS: Power and sample size calculation software version 3.1.2 (Vanderbilt University, Nashville, Tennessee, USA).

Data management and statistical analysis were performed using the Statistical Package for Social Sciences (SPSS) version 21. Numerical data were summarized using means and standard deviations. Comparisons between the two groups concerning normally distributed numeric variables were made using the $t$ test. For categorical variables, differences were analyzed with the chi-square test. All $p$ values are two-sided. $P$ values $<0.05$ were considered significant.

\section{Results}

The age of the group of congenital hypothyroid children $(\mathrm{CHC})$ and the group of typically developing children (TDC) was not significantly different (Table 1). Both groups were matched regarding gender distribution (Table 2).

DSI constituents' mean and standard deviation values, i.e., $\mathrm{F}_{0}$-high, I-low, MPT, and jitter\%, in both groups $\mathrm{CHC}$ and TDC. Comparison between both groups showed a significant difference $(P$ value $<0.05)$ regarding the DSI parameters. F0-high was significantly lower in $\mathrm{CHC}$ than TDC. MPT was significantly lower in $\mathrm{CHC}$ than TDC. However, there was no significant difference of I-low between CHC and TDC; also, there was no significant difference of jitter \% between CHC and TDC. The 
Table 1 Age of the congenital hypothyroid children (CHC) and typically developing children (TDC)

\begin{tabular}{llllllll}
\hline & \multicolumn{1}{ll}{ CHC } & & & TDC & & P value \\
\cline { 2 - 3 } & Mean & SD & & Mean & SD & \\
\hline Age & 7.9 & 0.346 & & 3.1 & 8.9 & 2.3 \\
\hline
\end{tabular}

$S D$ Standard deviation

\section{Discussion}

The goal of this study was to compare the values of DSI and its parameters between $\mathrm{CHC}$ and TDC to assess the voice quality of $\mathrm{CHC}$ receiving early THR objectively. The DSI was used for this investigation because it is a multi-parametric, easily applied method for objective speech quality evaluation. The index was proposed by Wuyts et al. [14] and correlated with parameters

Table 2 Gender distribution of the congenital hypothyroid children (CHC) and typically developing children (TDC)

\begin{tabular}{|c|c|c|c|c|c|c|}
\hline & & \multicolumn{2}{|l|}{$\mathrm{CHC}$} & \multicolumn{2}{|l|}{ TDC } & \multirow[t]{2}{*}{$P$ value } \\
\hline & & Count & $\%$ & Count & $\%$ & \\
\hline \multirow[t]{2}{*}{ Sex } & Females & 6 & 40.0 & 7 & 50.0 & 0.588 \\
\hline & Males & 9 & 60.0 & 7 & 50.0 & \\
\hline
\end{tabular}

Table 3 Comparison between congenital hypothyroid children $(\mathrm{CHC})$ and typically developing children (TDC) regarding the DSI and its parameters (I-low, $\mathrm{F}_{0}$-high, MPT, and jitter \%)

\begin{tabular}{|c|c|c|c|c|c|}
\hline & \multicolumn{4}{|l|}{ Group } & \multirow[t]{3}{*}{$P$ value } \\
\hline & \multicolumn{2}{|l|}{$\mathrm{CHC}$} & \multicolumn{2}{|l|}{ TDC } & \\
\hline & Mean & SD & Mean & SD & \\
\hline Lowest intensity (I-low) & 42.93 & 3.26 & 45.20 & 2.86 & 0.0679 \\
\hline Highest frequency ( $F_{0}-$ high $)$ & 359.27 & 28.72 & 601.71 & 58.40 & $<0.001^{*}$ \\
\hline MPT & 6.51 & 1.26 & 7.82 & 1.28 & $0.009^{*}$ \\
\hline Jitter\% & 0.88 & 0.12 & 0.91 & 0.17 & 0.547 \\
\hline DSI & 2.92 & 0.96 & 3.61 & 0.99 & 0.081 \\
\hline
\end{tabular}

SD Standard deviation

*Significant $P$ value $<0.05$

This table shows that there was significant difference between $\mathrm{CHC}$ and TDC groups as regard ( $F_{0}$-high and MPT); however, there was no significant difference between both groups as regard (I-low and jitter\%). There was no significant difference between $\mathrm{CHC}$ and TDC groups regards DSI

comparison of DSI values between $\mathrm{CHC}$ and TDC was not significantly different $(P=0.081)$. DSI in $\mathrm{CHC}$ was $(2.92 \pm 0.96)$ and in TDC was $(3.61 \pm 0.99)$ (Table 3$)$.

In TDC, males and females were compared with their DSI and its components (Table 4). In TDC, the results showed that the values of the DSI and its components were not substantially varied across gender $(P=0.186)$.

In $\mathrm{CHC}$, the values of the DSI and its parameters were compared between genders (Table 5). The F0-high, MPT, and jitter \% values did not vary significantly between males and females in CHC. I-low value for males was significantly lower than females $(p=0.019)$. The mean DSI value was significantly higher in males $(3.42 \pm 0.78)$ than in females $(2.13 \pm 0.72)$; the $p$ value was 0.023 .
Table 4 Comparison between males and females in typically developing children (TDC) for the DSI and its parameters (I-low, $\mathrm{F}_{0}$-high, MPT, and jitter \%)

\begin{tabular}{|c|c|c|c|c|c|}
\hline & \multicolumn{4}{|l|}{ TDC } & \multirow[t]{3}{*}{$P$ value } \\
\hline & \multicolumn{2}{|l|}{ Males } & \multicolumn{2}{|c|}{ Females } & \\
\hline & Mean & SD & Mean & SD & \\
\hline Lowest intensity (I-low) & 44.37 & 2.69 & 46.03 & 2.98 & 0.317 \\
\hline Highest frequency ( $F_{0}-$ high) & 612.43 & 50.74 & 590.22 & 67.41 & 0.522 \\
\hline MPT & 8.22 & 0.87 & 7.49 & 1.3 & 0.256 \\
\hline Jitter\% & 0.91 & 0.19 & 0.91 & 0.17 & 1.000 \\
\hline DSI & 3.99 & 0.52 & 3.23 & 1.23 & 0.186 \\
\hline
\end{tabular}

This table shows that there was no significant difference between males and females in TDC for the DSI and its parameters

Table 5 Comparison between males and females in congenital hypothyroid children $(\mathrm{CHC})$ for $\mathrm{DSI}$ and its parameters (I-low, $\mathrm{F}_{0^{-}}$ high, MPT, and jitter \%)

\begin{tabular}{|c|c|c|c|c|c|}
\hline & \multicolumn{4}{|l|}{$\mathrm{CHC}$} & \multirow[t]{3}{*}{$P$ value } \\
\hline & \multicolumn{2}{|l|}{ Males } & \multicolumn{2}{|c|}{ Females } & \\
\hline & Mean & SD & Mean & SD & \\
\hline Lowest intensity (I-low) & 41.18 & 2.35 & 45.47 & 2.49 & $0.019^{*}$ \\
\hline Highest frequency $\left(F_{0}-\right.$ high $)$ & 360.23 & 24.51 & 357.42 & 36.67 & 0.871 \\
\hline MPT & 6.23 & 0.89 & 6.93 & 1.57 & 0.318 \\
\hline Jitter\% & 0.89 & 0.15 & 0.87 & 0.08 & 0.749 \\
\hline DSI & 3.42 & 0.78 & 2.13 & 0.72 & $0.023^{*}$ \\
\hline
\end{tabular}

*Significant $P$ value $<0.05$

This table shows that the DSI and I-low were significantly different between males and females in $\mid \mathrm{CHC}$ however the $\mathrm{F}_{0}$-high and jitter $\%$ values were not significantly different 
of voice disorders [24]. Moreover, the DSI was used to compare voice quality to various groups of speakers [25]. The present study investigated the DSI and its parameters in all 15 children with congenital hypothyroidism receiving THR (mean age $7.9 \pm 3.1$ years) and 14 TDC (mean age $8.9 \pm 2.3$ years).

According to Wuyts et al. [14], the DSI assumed values ranged from negative to positive. A value of +5 identified standard voice quality, and a value of -5 represented severe dysphonic voice. Also, scores beyond that range were possible, marking healthy or deficient voice quality [16]. In the current study, the DSI value obtained for $\mathrm{CHC}$ was $(2.92 \pm 0.96)$ and for TDC was $(3.61 \pm 0.99)$, which means that there is no objectively recorded dysphonia via the multi-parametric index for $\mathrm{CHC}$, which are supplemented with thyroid hormone therapy.

The typical DSI values for children were not demonstrated in many studies. In a study to document the DSI scores in normal Indian children (8-12 years), Pebbili et al. [23] found that the DSI value was $3.29 \pm 1.33$, which was as close as the DSI value of typical children in the present study (3.61 \pm 0.99$)$.

Voice problems in patients with hypothyroidism were reported to range from 9 to $52 \%$ [26]. In a study of the objective values of different voice parameters in patients with hypothyroidism, Mohammadzadeh et al. [27] found that most voice parameters in hypothyroidism were impaired compared to reference typical values. With early treatment via levothyroxine to attain a standard range of thyroid hormones, better voice outcomes might be achieved [28]. The current study results confirmed that the DSI value for the treated congenital hypothyroid children was not significantly different from normal children $(P=0.081)$, which associates non-detected DSI objective voice alternations with early treatment for $\mathrm{CHC}$. It emphasizes the essential role of thyroid hormones for the normalization of laryngeal function, so it is mandatory to screen newborns for hypothyroidism to detect the need for early starting therapy. Mostly, newborns may not show the signs of thyroid hormone deficiency.

As far as we can tell, this study may be the first to use the DSI as a multi-parametric method for the objective assessment of voice quality in $\mathrm{CHC}$ treated with early THR. Birkent et al. [29] performed a study for patients with hypothyroidism who had total thyroidectomy to determine the effects of THR therapy on the objective vocal parameters. However, none of the multi-parametric objective voice tools were used; they executed voice analysis before and after THR by measuring the mean fundamental frequency $\left(\mathrm{F}_{0}\right)$, jitter, shimmer, amplitude perturbation quotient (APQ), pitch perturbation quotient (PPQ), noise-to-harmonics ratio (NHR), and MPT. They found that F0 in female patients was significantly decreased after thyroid hormone therapy while there were no significant changes of other objective voice parameters.

When we examined the separate constituents of DSI, we also found that the frequency-related parameter $\left(\mathrm{F}_{0}\right.$-high) was significantly lower in $\mathrm{CHC}$ receiving THR than TDC. This result explains that THR may increase fluids in vocal fold layers, which causes decreased voice range production and subsequent decrease of $\left(\mathrm{F}_{0}\right.$-high) parameter because it is a reasonably sensitive measure for small changes in vocal fold. Nevertheless, a slight effect of THR therapy on vocal folds might occur as vocal folds edema was not observed during laryngoscope examination.

In the present study, MPT was found to be significantly lower in $\mathrm{CHC}$ than TDC, unlike the finding of Birkent et al. [29]. It could be interpreted by the decrease of pulmonary function in hypothyroidism, although $\mathrm{CHC}$ was controlled. Some studies documented that they demonstrated voice-related sequelae beyond their hormonal status. Moreover, they found that exercise ability and tolerance were affected [30,31]. Furthermore, Biondi et al. [32] demonstrated that hypothyroid patients under levothyroxine treatment had impaired exercise capacity.

No dissimilarity in vocal quality for TDC within gender was found in the current study. When we assessed the values of DSI and its components, the DSI was not significantly different between males and females in TDC $(p=0.186)$. These results were not coinciding with the other studies that found variations in the objective voice parameters across gender. Pebbili et al. [23] found that DSI values for females were significantly higher than those for males in Indian TDC, with age ranging from 8 to 12 years $(P=0.027)$. Another study by Stathopoulos and Sapienza [33] suggested that in the same age range, male and female children were found to have a difference in acoustic voice values because the length of vocal folds in males is more significant and, the rate of vocal growth per year for males exceeds that of females. The present study's discrepancy of findings relative to others could be due to a small study population.

As for the DSI difference between males and females in $\mathrm{CHC}$ in this study, the DSI in females $(2.13 \pm 0.72)$ was significantly lower $(P=0.023)$ than males $(3.42 \pm$ $0.78)$. Within the $\mathrm{CHC}$ group, the I-low in females was significantly higher than in males $(P=0.019)$. It could be explained by that the softest intensity is a sensitive parameter for changes in voice quality. The deviance noticed in DSI is probable as females' lowest intensity parameter increases. Pebbili et al. [23] also attributed the results of higher values of DSI and I-low scores in females to the differences in anatomical and behavioral characteristics between male and female children. Another 
explanation made by Stathopoulos and Sapienza [33] was the physiological pattern of thoracic respiration during talking for females rather than abdominal respiration for males.

The small population size should be counted as a limitation of this study. Also, it may be the reason for nonsignificant DSI differences across gender in normal children. Unlike the group of CHC, DSI in females was significantly lower in males. Further studies should be performed with intervals of children's age to specify the DSI values for a small range of children and gain information about oncoming puberty.

\section{Conclusion}

This study is the first to use the multi-parametric DSI for the objective voice assessment of $\mathrm{CHC}$ early supplemented with thyroid hormone. This study revealed that the DSI values were not significantly different between $\mathrm{CHC}$ receiving early THR and TDC. However, there was a significant difference between both groups regarding two DSI parameters (MPT and $\mathrm{F}_{0}$-high).

Therefore, this study demonstrates the importance of early screening and treatment for congenital hypothyroidism to prevent further voice problems. Additionally, it can provide the initial information about the DSI values for normal Arabic-speaking children.

\section{Abbreviations}

CHC: Congenital hypothyroid children; TDC: Typically developing children; DSI: Dysphonia severity index; $F_{0}$-high: Highest frequency; I-low: Lowest intensity; MPT: Maximum phonation time.

\section{Acknowledgements}

We show our gratitude to the professors of the department for sharing their expertise with us during this research. We thank Olfat Gad the copy editor for language editing of this work.

\section{Authors' contributions}

HF conceived the study and wrote the manuscript. AFA acquired the data. AA analyzed the data. HS revised the manuscript. The author(s) read and approved the final manuscript.

\section{Funding}

No funding was received for this work.

\section{Availability of data and materials}

The dataset generated during this study are available from the corresponding author.

\section{Declarations}

\section{Ethics approval and consent to participate}

The study was approved by the ethical committee of the ENT Department, Faculty of Medicine, Cairo University, number 25/2015. The study was carried out from January 2016 to June 2016. Informed consent was obtained from the parents for their children participation in this research.

\section{Consent for publication}

Not applicable

\section{Competing interests}

The authors declare that they have no competing interests.

\section{Author details}

${ }^{1}$ Phoniatrics, Phoniatric Unit, ENT Department, Faculty of Medicine, Cairo University, Giza, Egypt. ${ }^{2}$ Diabetes, Endocrine, and Pediatric Unit (DEMPU), Cairo University Children Hospital, Cairo, Egypt.

Received: 9 November 2021 Accepted: 4 January 2022

Published online: 24 January 2022

\section{References}

1. Ryu CH, Han S, Lee MS, Kim SY, Nam SY, Roh JL et al (2015) Voice changes in elderly adults: prevalence and the effect of social, behavioral, and health status on voice quality. J Am Geriatr Soc. 63:1608-1614. https:// doi.org/10.1111/jgs.13559

2. Michelsson K, Sirvio P (1976) Cry analysis in congenital hypothyroidism. Folia Phoniatrica (Basel) 28:40-47. https://doi.org/10.1159/000264029

3. Van Lierde KM, Claeys S, De Bodt M, Van Cauwenberge P (2006) Response of the female vocal quality and resonance in professional voice users taking oral contraceptive pills: a multi-parameter approach. Laryngoscope. 116:1894-1898. https://doi.org/10.1097/01.mlg.0000235917.06088.b1

4. Locke JL, Hauser MD (1999) Sex and status effects on primate volubility: clues to the origin of vocal languages? Evol Hum Behav. 20:151-158

5. Bargagna S, Canepa G, Costagli C, Dinetti D, Marcheschi M, Millepiedi S (2000) Neuropsychological follow-up in early-treated congenital hypothyroidism: a problem-oriented approach. Thyroid. 10(3):243-249. https:// doi.org/10.1089/thy.2000.10.243

6. Maciel LMZ, Kimura ET, Nogueira CR, Mazeto GM, Magalhães PKR, Nascimento ML et al (2013) Congenital hypothyroidism: recommendations from the Thyroid Department of the Brazilian Society of Endocrinology and Metabolism. Arq Bras Endocrinol Metab. 57(3):188-192. https://doi. org/10.1590/s0004-27302013000300004

7. Pezzuti IL, Lima PP, Dias VMA (2009) Congenital hypothyroidism: clinical profile of newborns identified by the Minas Gerais Neonatal Screening Program. J Pediatr. 85(1):72-79. https://doi.org/10.2223/JPED.1863

8. Gupta OP, Bhatia PL, Agarwal MK, Mehrotra ML, Mishr SK (1977) Nasal, pharyngeal, and laryngeal manifestations of hypothyroidism. Ear Nose Throat J. 56:349-356

9. Ritter FN (1964) The effect of hypothyroidism on the larynx of the rat. An explanation for hoarseness associated with hypothyroidism in the human. Ann OtolRhinoLaryngol. 73:404-416. https://doi.org/10.1177/ 000348946407300212

10. Altman KW, Haines GK 3rd, Vakkalanka SK, Keni SP, Kopp PA, Radosevich JA (2003) Identification of thyroid hormone receptors in the human larynx. Laryngoscope 113:1931-1934. https://doi.org/10.1097/00005537200311000-00014

11. Stollberger C, Finsterer J, Brand E, Tschabitscher D (2001) Dysarthria as the leading symptom of hypothyroidism. Am J Otolaryngology 22:70-72. https://doi.org/10.1053/ajot.2001.20698

12. Boero D, Weber G, Vigone MC, Lenti C (2000) Crying abnormalities in congenital hypothyroidism: preliminary spectrographic study. J Child Neurology. 15(9):603-608. https://doi.org/10.1177/088307380001500906

13. Eadie TL, Doyle PC (2005) Classification of dysphonic voice: acoustic and auditory perceptual measures. J Voice 19:1-14

14. Wuyts FL, DeBodt MS, Molenberghs G et al (2000) The dysphonia severity index: an objective measure of quality based on a multi-parametric approach. J Speech Lang Hear Res. 43:796-809. https://doi.org/10.1044/ jslhr.4303.796

15. Aichinger $P$, Feichter $F$, Aichstill B et al (2012) Inter-device reliability of DSI measurement. Logoped Phoniatr Vocol. 37:167-173. https://doi.org/10. 3109/14015439.2012.687761

16. Hakkesteegt MM, Brocaar MP, Wieringa MH et al (2006) Influence of age and gender on the dysphonia severity index. A study of normative values. Folia Phoniatr Logop. 58:264-273. https://doi.org/10.1159/000093183

17. Shah RK, Woodnorth GH, Glynn A et al (2005) Pediatric vocal nodules: correlation with perceptual voice analysis. Int J Pediatr Otorhinolaryngol. 69:903-909. https://doi.org/10.1016/j.ijporl.2005.01.029 
18. Jiang JJ, Zhang Y, MacCallum J et al (2009) Objective acoustic analysis of pathological voices from patients with vocal nodules and polyps. Folia Phoniatr Logop. 61:342-349. https://doi.org/10.1159/000252851

19. McAllister A, Sederholm E, Sundberg J et al (1993) Relations between voices range profiles and physiological and perceptual voice characteristics in ten years old children. J Voice 8:230-290. https://doi.org/10.1016/ S0892-1997(05)80294-2

20. Reynolds V, Buckland A, Bailey J et al (2012) Objective assessment of pediatric voice disorders with the acoustic voice quality index. J Voice 26:672e1-672e7. https://doi.org/10.1016/j.jvoice.2012.02.002

21. Grosse SD, Van Vliet G (2011) Prevention of intellectual disability through screening for congenital hypothyroidism: how much and at what level? Arch Dis Child. 96:374-379. https://doi.org/10.1136/adc.2010.190280

22. Dimitropoulos A, Molinari L, Etter K et al (2009) Children with congenital hypothyroidism: long-term intellectual outcome after early high dose treatment. Pediatr Res. 65:242-248. https://doi.org/10.1203/PDR.0b013 e31818d2030

23. Pebbili GK, Kidwai J, Shabnam S (2017) Dysphonia severity index in typically developing Indian children. J Voice. 31:125.e1-125.e6. https://doi. org/10.1016/j.jvoice.2015.12.017

24. Kooijman PG, de Jong Fl, Oudes MJ, Huinck W, van Acht H, Graamans K (2005) Muscular tension and body posture in relation to voice handicap and voice quality in teachers with persistent voice complaints. Folia Phoniatrica et Logopaedica 57:134-147. https://doi.org/10.1159/000084134

25. Timmermans B, De Bodt MS, Wuyts FL, Boudewijns A, Clement G, Peeters $A$, Van de Heyning P (2002) Poor voice quality in future elite vocal performers and professional voice users. Journal of Voice 16:372-382. https://doi.org/10.1016/s0892-1997(02)00108-x

26. Carding PN, Roulstone S, Northstone K; ALSPAC Study Team (2006) The prevalence of childhood dysphonia: a cross-sectional study. JVoice 20:623-630. https://doi.org/10.1016/j.jvoice.2005.07.004

27. Mohammadzadeh A, Heydari E, Azizi F (2011) Speech impairment in primary hypothyroidism. J Endocrinol Invest. 34:431-433. https://doi.org/ 10.1007/BF03346708

28. Jones JH, Gellen B, Paterson WF, Beaton S, Donaldson MDC (2008) Effect of high versus low initial doses of L-thyroxine for congenital hypothyroidism on thyroid function and somatic growth. Arch Dis Child. 93:940-944

29. Birkent H, Karaalioglu O, Morati AL, AkcamT GM (2008) Prospective study of the impact of thyroid hormone replacement on objective voice parameters. Ann Otol Rhinol Laryngol 117:523-527

30. Caraccio N, Natali A, Sironi A, Baldi S, Frascerra S, Dardano A et al (2005) Muscle metabolism and exercise tolerance in subclinical hypothyroidism: a controlled trial of levothyroxine. J Clin Endocrinol Metab. 90(4057):4062. https://doi.org/10.1210/jc.2004-2344

31. Fontana M, Passino C, Poletti R, Zyw L, Prontera C, Scarlattini M et al (2012) Low triiodothyronine and exercise capacity in heart failure. Int. J Cardiol. 71:54-153

32. Biondi B, Fazio S, Cuocolo A, Sabatini D, Nicolai E, Lombardi G et al (1996) Impaired cardiac reserve and exercise capacity in patients receiving long-term thyrotropin suppressive therapy with levothyroxine. J Clin Endocrinol Metab. 81:4224-4228. https://doi.org/10.1210/jcem.81.12. 8954019

33. Stathopoulos ET, Sapienza CM (1997) Developmental changes in laryngeal and respiratory function with variations in sound pressure level. J Speech Lang Hear Res. 40:595-614. https://doi.org/10.1044/jslhr.4003.595

\section{Publisher's Note}

Springer Nature remains neutral with regard to jurisdictional claims in published maps and institutional affiliations.

\section{Submit your manuscript to a SpringerOpen ${ }^{\circ}$ journal and benefit from:}

- Convenient online submission

- Rigorous peer review

- Open access: articles freely available online

- High visibility within the field

- Retaining the copyright to your article

Submit your next manuscript at $\boldsymbol{\nabla}$ springeropen.com 